\title{
REVIEW ON INTEGRATION OF BIG DATA IN IOT AGRICULTURE SYSTEM
}

\author{
${ }^{1}$ Sharmila Gaikwad, ${ }^{2}$ Jignesh Patil \\ ${ }^{1}$ Assistant professor, ${ }^{2}$ Under graduate student, BE in Computer Engineering \\ Rajiv Gandhi Institute of Technology, Mumbai \\ sharmila.gaikwad@mctrgit.ac.in,jigpatil1999@gmail.com
}

\begin{abstract}
Agriculture is a field where many changes are accepted in order to produce a high-quality output. We know that there are several forms of irrigation, such as old irrigation, sprinkler irrigation, and drip irrigation, all of which are integrated or converted in the IOT, but there are a few things we need to modify in the irrigation, primarily crop protection and disease prevention. We can save the crop from the pest, but we must first understand the crop's power. Crop strength has recovered from the critical stage to the normal stage, but agriculture activity must be managed with precision. Different algorithms, such as Map-Reduce and Recommendation System, are available in big data. We will concentrate on crop protection in this research.
\end{abstract}

\section{INTRODUCTION}

Due to the imbalanced character of the Indian agrobusiness, there are only 2-5 percent prospects of safe agronomy in the current circumstances. According to each survey, agriculture contributes 67 percent to India's economic strength. India is one of the world's most populous Agrobusiness provides 35 percent financial strength to Indian finance during pandemics, while agronomy provides 52 percent of India's budget in recent years. As a result, we can conclude that agriculture is the backbone of India's economy, and that if the climatic situation is in balance, agriculture is the safest vocation in the country. Agriculture is difficult and involves a lot of effort; agriculturalists face a variety of challenges, including poor weather conditions, financial administration, and incorrect crop seeds on the market. For the survey, we have chosen a specific area. We all know how big farming is, so as we travel to different places, the atmosphere, water quality, and soil quality all change. We chose North Maharashtra for this study because the soil is black and the average temperature is around 30 degrees. Crop management is divided into two seasons.:

Kharif Crop: Cotton, Pigeon Pea, Green Gram, Black Gram, Bajra, Jowar etc.

Rabi Crop: Wheat, Groundnut, Sunflower, Cicers, Maize, Mustard etc.

\section{LITERATURE REVIEW}

This literature survey consists of different sections:

1) Machine Learning: Learning is the process of defining new algorithms for a system and then repeating the old version algorithm with certain changes. With some planning and instructions from the client, the system is created by the real developer. For prediction and analysis, we have mastered many machine learning methods such as naive bayes, logistics, and k-mean. For more precision and efficiency, analysis yields various findings and results. For classification and regression of picture data sets, the Random Forest classifier is utilised to produce speedy choices.

2) Big Data: Since data is the most important component of any company, we need a high container to load large amounts of data. The HDFS container is made up of HDFS files (Hadoop Distributed File System). In agriculture, big data is required for data collection and storage. For crop pest analysis and accuracy, survey map reduce is used. Splitting and mapping data into smaller datasets as simple datasets is how Map Reduce works.[1-4]

3) IOT Based: In other countries and some regions of India, practically all water sprinkling is based on web and embedded technology, which is an invention in the field of husbandry. Irrigation is becoming more inventive because to the use of solar energy and the Internet of Things[5]. Everyone may now simply monitor their farm from a single location. Due to improved components and extensive research, IOT irrigation is on the verge of becoming a success. 


\section{ANALYSIS OF COTTON}

We have Chosen Kharif Harvest for paper to rise production using big data and different technology:

1. Cotton: North Maharashtra is the region of Maharashtra that produces a large amount of cottons. Cotton is grown in these areas of NM (Jalgaon, Dhule, Nandurbar, Nashik).

a) Planting takes place from the end of May to the beginning of June. Cotton is grown for almost 120180 days from May to December.

b) Irrigation: There are two types of irrigation:

1) Irrigation System (Old)

2) Irrigation via Drip

Drip irrigation is now the most popular method of irrigation. Cotton is manufactured at a rate of 80 to 90 percent, followed by ancient irrigation.

Drip irrigation has the following benefits:

- Less water waste in the field saves money and time.

- It yields better results than simple irrigation in terms of both quality and quantity.

- It reduces the amount of medicine and insecticides that must be spread by using drip lines.

c) Disease: Cotton disease manifests itself in stages, each of which has a different influence on the crop, as shown below:

1) Aphis gossypii: It affects the cotton leaf and lowers the quality of the cotton.

2) Leaf Hopper: It turns the leaf yellowish, then brownish in the last stages.

3) White-flies: They have a significant and negative impact on the veins of the leaf, causing the leaf to turn in poor conditions.

4) Boll Weevil: When female boll weevils lay its eggs in blossoms and fruit, it has a significant influence on cotton production, causing farmers to lose money.

c) Weather:

- Flowering Quantity: When there is a lot of rain, flowering quantity decreases, which has an impact on crops and productivity.

- It does not require a cloudy climate, which reduces cotton yield.

- Time management has a greater impact on cotton, such as planting cotton seeds at inopportune times, watering crops according to their needs, and crop leaf damage if there is a gap in water planning..

\section{PROPOSED MODEL}

Drone based IOT irrigation using Big Data (Map Reduce and Recommendation System).

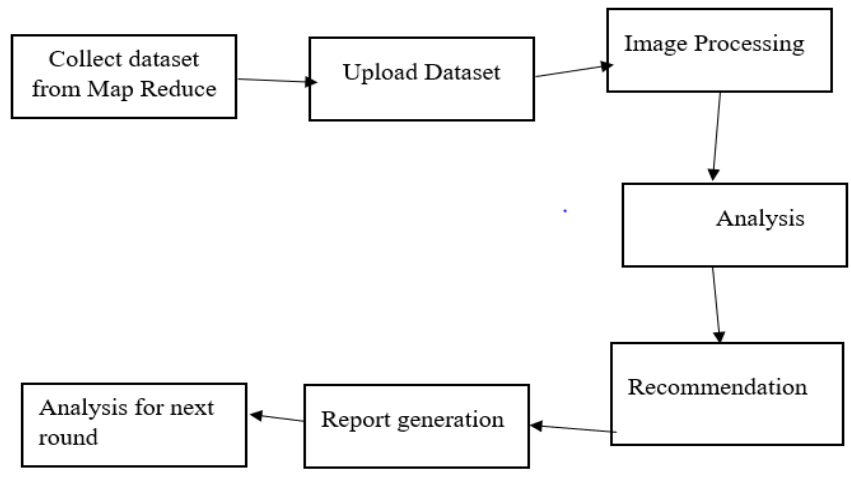

Figure 1: Proposed Model

1) Create an algorithm in the drone: In order to capture images of cotton, we must create an algorithm in the drone that will cause the camera to scan the entire crop from top to bottom, covering the entire field. It will be used to store photos in a database. (Random Forest and Tree Classifier is a random forest and tree classifier.)

2) Dataset: The dataset created by map reduction will be used to feed the recommendation system.

3) Upload Dataset: For crop scanning, the dataset will be uploaded in a drone using a machine learning technique.

4) Image Processing: Crop health, water and soil management, and pesticide requirements.

5) Analysis: How many pesticides are required based on the disease on the crop?

6) Report Generation: It will provide specific information about the farm, such as how much area the drone covers, soil moisture, crop health, and future tasks.

7) Analysis for the next round: modifying the algorithm for future use, removing ineffective pesticides from the system, and incorporating a new algorithm for future use.

\section{ARCHITECTURE}

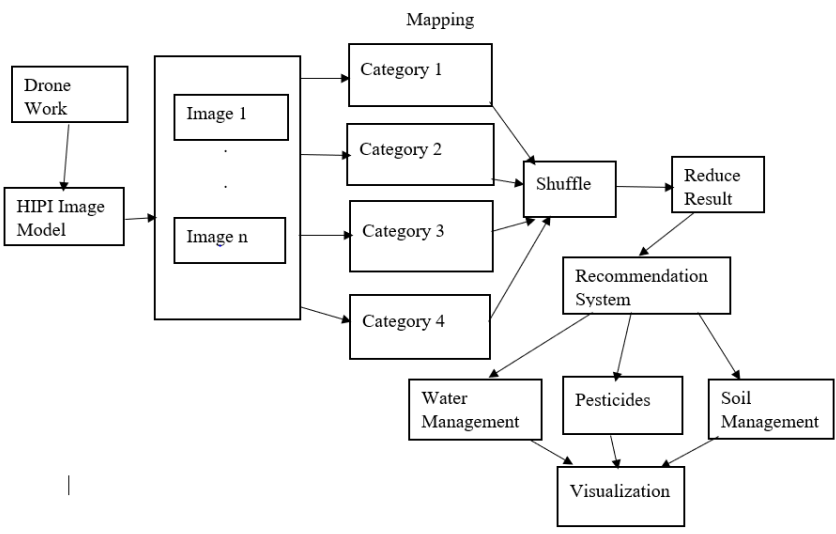

Figure 2: Architecture of Drone Based IOT Irrigation 
Drone is the initial component, and it rotates, scans photographs for cropping, and stores images in a database. Machine learning will be used to create algorithms for crop detection and disease detection[6]. (Support Vector Machine, Artificial Neural Networks, and so on. (Hadoop Image Processing Interface) Hadoop Image Processing HIPI is an Apache Hadoop image processing library[7]. It provides high-resolution image storage in the device. When a disease category occurs on a crop, it will aid in the creation of a large dataset generated. When crop monitoring begins, a camera captures $n$ numbers of photographs of the crops, which are then saved in the database. As described in the cotton analysis, photographs of the crop are sorted into several categories. Map breaks the images big dataset into some groups, and shuffle sends the result of the map to the reduce phase. The reduce phase reduces the number of categories to a manageable number.

We understand what a recommendation system accomplishes in big data. Take, for example, an e-commerce website where the developers target client history for product sales and special offers. We'll use the recommender system to suggest water management (is there a requirement for water in the soil), pesticides (which type of medicine is needed based on crop illness), and soil management (quality of the soil is bad or good).Visualization will create a record of the farm as well as a report that will be sent to the user.

\section{RESULTS}

\begin{tabular}{|l|l|l|}
\hline Parameters & 2010 to 2014 & 2015 to 2021 \\
\hline $\begin{array}{l}\text { Boll Weevil } \\
\text { Insect }\end{array}$ & $10 \%$ & $30 \%$ \\
\hline Climate & $50 \%$ & $75 \%$ \\
\hline $\begin{array}{l}\text { Water } \\
\text { Management }\end{array}$ & $0 \%$ & $50 \%$ \\
\hline Soil & $20 \%$ & $40 \%$ \\
\hline Faulty Seed & $30 \%$ & $90 \%$ \\
\hline
\end{tabular}

Table 1: Analysis of cotton with different parameters and year

As per analysis of authors, data which is collected and shown in the above table.

- The Boll weevil bug has a $10 \%$ effect from 2010 to 2014, and a 30\% effect from 2015 to 2021.

- Climate plays an important role in agriculture; practically all agricultural productivity is influenced by the weather. Climate change, according to reports from the last few years, is having an impact on productivity. Due to severe rains, crop health might deteriorate to the point of being unhealthy. Cotton height is diminished or the crop dies if there is less rainfall.

- Due to various irrigation types such as old irrigation, drip irrigation, sprinkle irrigation, and IOT irrigation, water management changes on a daily basis.

- Soil: Soil management is dependent on the condition of the soil; when the soil quality is assessed by a soil quality tester, he allows you to utilise natural and chemical fertilisers to boost production.

- Faulty Seed: Between 2018 and 2020, the number of faulty seeds will increase by $90 \%$ due to incorrect calculation and measurement during seed manufacture

According to study, 40 IoT Agro startups are in the works, which will provide agriculture a boost and make farming easier.

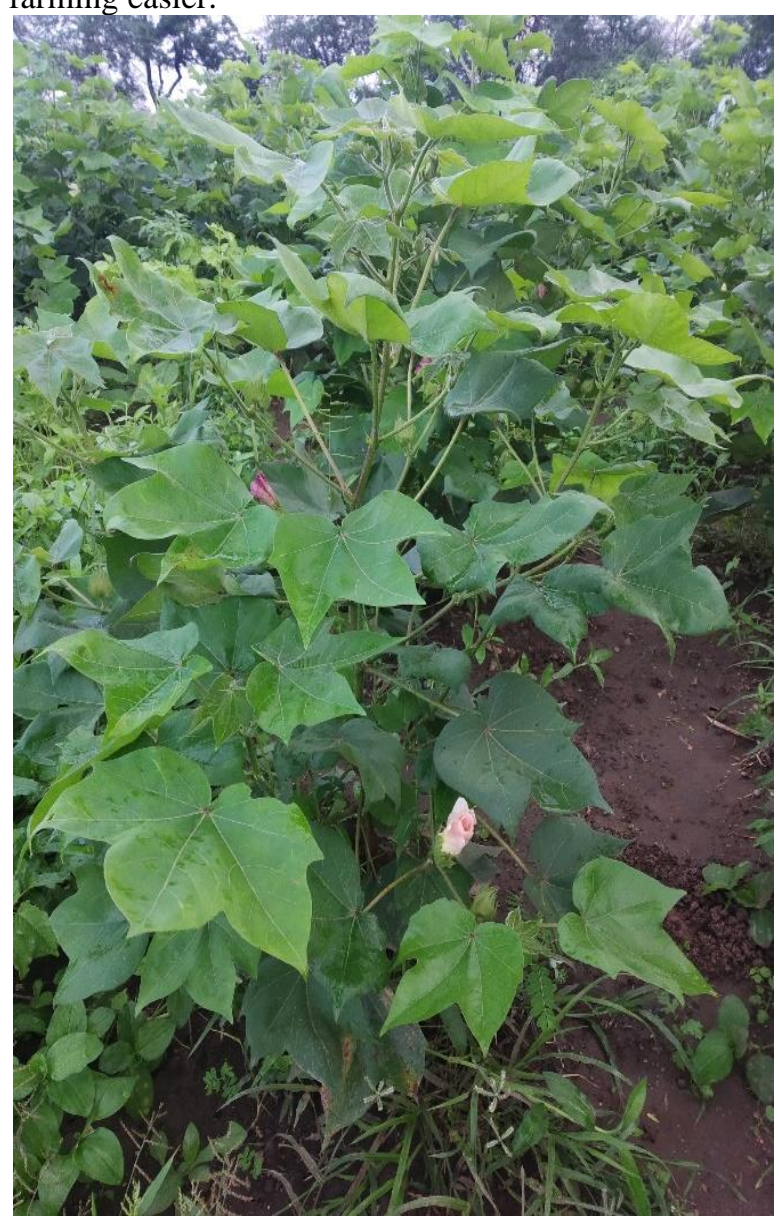

Figure 3: Cotton Crop with Flower 


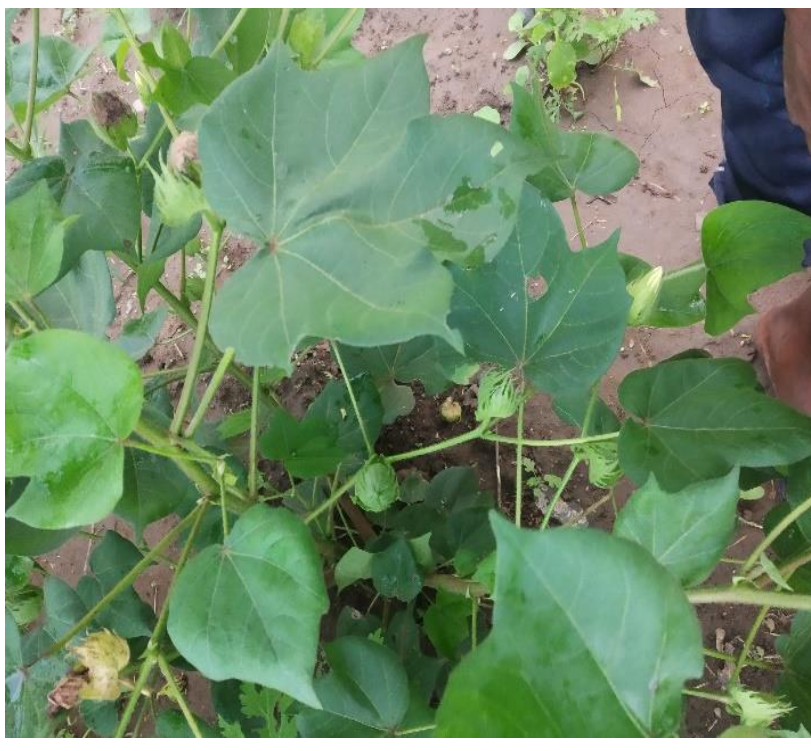

Figure 4: Cotton Crop with Fruit

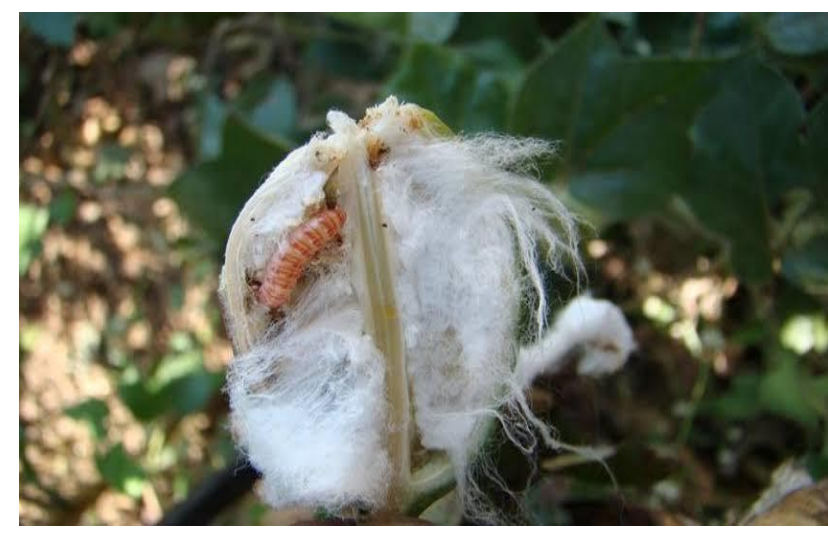

Figure 5: Cotton Crop with Boll weevil insect in cotton fruit

\section{CONCLUSION}

We can deduce that this system will produce more efficient results than other systems. Integration of three technologies into one system makes it more powerful than other systems. The system for cotton analysis will rely heavily on image processing and big data. The overall count of the disease crop and the safe crop will be aided by the prediction of map decrease. Because today's age is going toward IoT, we've combined several IoT and Big Data concepts to create a powerful system that will benefit the agricultural sector. We can improve the system for all crops, not only cotton, but we will need that much effort and research on the working field as well as in technology. Technologies is evolving at a rapid pace, and by utilising new technology, we can make some changes to the agricultural sector. In India, we now use BG Cotton 2nd Generation for production, while America uses 7th Generation BT Cotton. We've also modified the seed for improved production and chemical fertiliser to save agriculture. According to study, cotton production will decrease in 2020 due to faulty seed cotton and the Boll Weevil. (We can salvage cotton from these insects in the first, second, and third stages, but the ultimate stage is almost fatal to cotton.)

\section{REFERENCES}

[1] Big data Analysis: Recommendation System with Hadoop framework, Jai Prakash Verma, Bakim Patel, Atul-Patel,IEEE,2015,pg(92-97) 10.1109/CICT.2015.86

[2] Classifying Agricultural Crop Pest Data Using Hadoop Map Reduce Based C5.0Algorithm, Revathy Rathinasamy,S Balamurali, LawranceRaj,2019, $\operatorname{Pg}(394-411), 10.13052 / j \operatorname{csm} 2245-1439.835$

[3] Big Data and its impact on agriculture, Pal Ribaries, Ecocycles,pg(33-34),10.19040/ecpcycles.v2i154

[4] Big Data Analytics for Crop Preduction Mode using Optimization technique, Shivi Sharma, GeetanjaliRathee,HemrajSaini,2018,pg(760-763), 10.1109/PDGC.2018.8746001

[5] Smart Irrigation System Using Internet of things, Alak Roy, Jayanta Pal,2020,pg(119-129),10.1007/978-981156198-6-11

[6] Plant Disease Detection Using Machine Learning, ShinaRamesh,RamchandraHebbar,InternationalConfer enceonDesignInnovationsfor3CsComputeCommunicat ionControl,pg(41-45),10.1109/ICDI3C.2018.00017

[7] Hadoop and Its role in Modern Image Processing, Seyed-Mojtaba Banaei, Hossein Kardan Moghaddam, OJMS,2014,pg(240-244), 10.4236/ojms.2014.44022 